\title{
'I get up, because I know I can go to my group today': Examining the Healing Power of Relationship in Support Groups
}

\author{
Abraham Francis \\ Department of Social Work and Human Services, James Cook University, Douglas, Townsville QLD 4811, Australia \\ *Corresponding Author:abraham.francis@jcu.edu.au
}

\begin{abstract}
Mental illness, whether a continuous condition or an intermittent occurrence, leads to a range of consequences that ultimately has an impact on the lives of people with mental illness. These experiences are so unique, different and difficult for them especially for those living in rural and remote communities. In this context, social isolation,difficulties in following through the individual recovery plan and maintaining relationships are some of the issues confronting people with a mental illness. While there are a number of strategies made to address these issues, the author in this paper particularly discusses the process of moving from playing scrabble with a group of consumers to establishing a mental health support group in a rural Australian context that provided ongoing mutual support to the consumers and narrates the significance of relationships in the lives of people with mental illness. The helping relationship between workers and consumers and between workers and families is seen as fundamental to the healing process (Bland, Renouf, \& Tullgren, 2009). In this paper, the author based on his experiences examines the process of building this relationship among the members with the support of group activities, identifies the importance of the relationship and describes the process of facilitation and its outcomes. The author discusses both the strengths and the challenges faced by the consumers, the practitioners and the wider community in establishing both a support group and in maintaining relationships. Italso presents the theoretical underpinnings of this work, offers critical reflection on practice and suggests implications for mental health social work practice.
\end{abstract}

Keywords Support Group, Consumers, Healing Process, Social Work

\section{Introduction}

Support groups offer mutual understanding and help in dealing with ongoing stressors for people with mental health issues. Groups also play an important role in peoples' journey towards recovery in mental health (Francis, 2012). A study by McWilliams et al., (2010) found that groups are an important, though often overlooked, part of a person's holistic recovery. Hyde (2013) notes that data collected from a seven year review of outcomes of mutual aid groups in the mental health sphere indicate consumers highly valued the supportive and collaborative nature of such groups. Support groups are an ideal area of mental health social work practice in the delivery of recovery-focused services. Svavarsdottir, Olafsdottir, Sturludottir, \&Juliusdottir, (2012) explored a research question - "How does group work best serve the mentally ill and what elements of the group work are most beneficial to them?' (p.116). The study found that the participants of this research study were very positive about group work and believed that it made positive, practical, and/or emotional contributions to their lives. The participants of this study also believed that by participating in group work activities, there has been marked improvements in their overall wellbeing as has been portrayed through the four themes that emerged from the analysis. The themes identified from the interview analyses are communication and social life, support and empowerment, empathy and trust, and practical advice and guidance.The authors confirm that group work has considerable value in the treatment of persons with mental illness. Working with groups is a method which allows group members to help each other, empowers them, and provides opportunity for reciprocation by helping others as they help themselves. Wodarski, \&Feit, (2012) propose that working with groups has been shown to require less of a therapists time and resources when compared to individual therapy.

While the role groups play in an individual's life is critical in recovery efforts, in this article, the author intends to describe the power that exists in a group and describe how a support group can offer personal and fulfilling experiences to overcome the pain and social isolation that people with mental illness often face in their day to day life. Using two 
case vignettes, the author illustrates the healing power that transforms both the life of the consumer and of the group itself. Drawing on the personal experiences and lessons from the work, the author argues for the implementation of such models in the delivery of services and advocates the necessity to include it in the social work education curriculum. Some of the goals of this support group were to provide people with a mental illness a safe and supportive environment where they can meet and interact without fear and judgment from people and society. It also aimed to provide education for illness management and help members address social isolation, redeem self-esteem and hope, and improve their life situation. In this paper, the author also examines the process of building the relationship among the members through support of group activities, identifies the importance of relationships and describes the process of facilitation. Two case vignettes are discussed in this article to indicate the power of the group and how it influences the members to overcome fears, social isolation and improve their lives. It also showcases the healing power of relationships that can be experienced in groups and the very nature of community support which are fundamental to the sustainability of such groups in rural communities.

\section{The Context}

I was employed as a social worker in a rural area in Australia where my primary responsibility was to set up an emotional wellbeing program for the local rural community with a special focus on mental health issues. The ideas for setting up a support group came from one of the consumers who was active in this area for many years. With the support of a Non-Governmental Organization (NGO) in the area we decided to set up a support group for the wellbeing of people who had mental health issues. The program was supported by the local community mental health team and thelocal NGO. The Non-Government organization provided us with the initial space for the group to meet, while the community mental health team provided staff to run the project. Thus, this became one of my roles to develop and run a support group. After the initial planning with a few consumers and the partner agency, the program was launched in 2006 in a rural town in Australia.

\section{The Background and Profile of the Participants}

The participants were people who were diagnosed with a mental illness and who were living in the project area at the time of the service. Both males and females attended the group on a regular basis. The inclusion criteria were that anyone with a mental health problem could access the group activity. While the majority of the members had a long standing mental illness, there were also members who participated in the group as they were experiencing social isolation. So the nature of the group was in itself heterogeneous and the only commonality was their willingness to participate in group activities which provided an opportunity for social interaction and enjoyment in some activities which gave them a sense of satisfaction and achievement.

Mostly people came from the rural areas. Some had to travel up to two hours to attend the group. Transport was provided to members who did not have access which made it easy for some of the members to attend the support groups. Combating social isolation was a major issue for many participants. Most participants were affected by serious, long-term psychiatric conditions and many had substantial histories of hospitalisation. People with mental illness often talked about having no sense of purpose and doubted their self-worth. Hence, redeeming a sense of self-esteem and hope for the future was a common theme for the group. Many members had a devalued self-concept, considered themselves as losers, or viewed themselves as "mental patients" not worthy of anything. Some are angry at how they have been treated by their own former friends, or by the mental health system itself. This briefly portrays the background of our group members. But in my observation, they all had one thing in common - a desire to get well and to stay well, for which they were ready to give it a crack.

\section{The Structure of the Group}

On the first day we only had two consumers who turned up to attend the group and we did not have any specific activities planned as it was decided that we will wait for more members to join first and then will decide the programme to make it more participatory in nature. The only resource that the members could find there was a game of Scrabble. Hence we played "scrabble "to just keep the group going. McDermott (2002) notes that the first meeting "is important in building trust and working towards establishing some cohesion"'(p.163).This was a crucial period for the group as we discussed how we could enroll more members and develop activities that would attract more to join in. It is the trust and confidence among the participants that allowed more members to come in. As the weeks passed by we had more members coming in. The recruitment at this stage was limited to a word of mouth approach. In the meantime we also introduced serving lunch at the group which was an attraction for many consumers. This is a brief description of the formation and start of the group. What is important to note here is the gradual development of the ideas, engaging with clients in meaningful activities, members taking initiatives to invite more members and a sense of cooperation and confidence among the members.

Within a year of its commencement, due to the increased number of participants(the numbers had gone up from 14 to 30 in 2007), we had to split the group in to two in two 
different locations. This second group met once a week on Thursdays from $10-2 \mathrm{pm}$, with various activities like meditation, physical exercises, workshops, picnics, games, mindfulness practice, yoga, fun activities etc. The management of the group, although with the facilitator, was transferred to the consumers themselves and a management committee was formed to oversee the functioning of the group in 2010. The paper further discusses the magnetic power of this group to support and transform its members on their way to recovery not just as a support group alone but as compassionate companions (Francis, 2012) in their life.

\section{What is a Support Group?}

Support groups offer mutual understanding and help in dealing with ongoing stressors. A support group provides an opportunity for group members to share skills, knowledge and experiences (McDermott, 2002, p.115). This establishes a connection between client need and group purpose (Kurland \& Salmon, 2006). Groups enable different ideas to come together and can provide diversity which can be valuable by gaining different perspectives when talking about issues and topics (Engleberg\& Wynn, 2007, p.16). Groups can give people the opportunity to make friends, socialise and feel part of a team which aligns with the groups aims. The recognition that others have lived through similar experiences and survived is enormously comforting. In most groups members will try to educate each other about new developments in their specific area of interest, about resources and coping strategies that have proved beneficial. The group described here has many of the characteristics of peer support groups in being free, ongoing, with no time-limitations or attendance requirements (McDermott, 2002). It also offers information about the conditions that bring them to the group. Moreover, the members decided what they wanted to achieve out of this group interaction. As human beings we are all part of several groups and our life is interconnected with many social relationships. Groups do play a role in our life. In the words of McDermott (2002) a group is-

' bounded social experience, with interaction between members, which includes an objective element - it exists in time and space and is visible and tangible, and a subjective element, which is felt, created and co-constructed in the minds, bodies and intellects of participants'. The element of communication between members adds to the collaborative experience of group work (p. 7).

When people are affected by serious mental illness or traumatic situations they are either cut off from this interconnectedness or relationship with one another due to many factors such as relationship breakdowns, financial loss, loss of jobs, loss of health, lack of self-esteem, by themselves, or can deliberately withdraw from the situation, fearing that they will not be understood or will be looked down upon by the community. In such situations, support groups emerge as a viable option for them. There is a lot of literature that specifies importance of support groups in the lives of people. Participation in family groups, peer groups, and classroom groups helps members learn acceptable norms of social behavior, engage in satisfying social relationships, identify personal goals, and derive a variety of other benefits that result from participating in closely knit social systems (Toseland\& Rivas 2012, p. 2)

In common terms a support group is a gathering of people who share a common concerns, health concern, interest, or who face similar issues. Members of support groups often share experiences and they sit and talk with other people who are in the same situation. A support group can help anyone cope better and feel less isolated as they make connections with others facing similar challenges. However, a support group is not a replacement of one's medical care but it can be a valuable resource to help you cope. A support group usually focuses on a specific situation or condition, such as breast cancer, diabetes, heart disease, addiction or long-term caregiving, mental health for example. It is also important to recognize that support groups are not the same as group therapy sessions. In support groups, the main thrust is to provide a safe place for people to come together and to be connected with others who may have experienced similar issues in their lives. I have observed and learned from my own clinical experience that feeling safe, and nonjudgmental listening, is pivotal for group members to be actively involved with such group programs.

In the group setting people discover that they are not alone in having particular feelings and thoughts (Toseland \& Rivas, 2012). The group setting can validate and normalize the experience of issues that people live with, and validation and normalization are empowerment characteristics of effective support groups. Participants in an effective group can empathise with each other, learn from each other and provide social support (Toseland \& Rivas, 2012). Support groups have increased rapidly in number and become a viable alternative to service provision. Support groups are a collection of like-minded individuals who meet together regularly to share and to learn from one another (Schopler \&Galinsky, 1995). It has been highlighted that people with passion and shared needs are the bedrock of support groups (Klein, 2000, as cited in Mohr, 2004, p.66). In recent times, support groups have assumed greater visibility and importance in the therapeutic and political arena and have become potent sources of education, empowerment, and advocacy. (Mahor,2004,p.75). Some of the Support groups combine different forms of intervention such as psychological or educational skills training, and emotional support (Burks, Lund, \& Hill, 1991). 'Support groups are led by members who have experience as caregivers, but they can be co-led by professional service providers, such as nurses, physicians, substance abuse counselors, social workers, or psychologists. Many member-run self-help groups use professional advisers' (Mohr, 2004, p.62).

There are a number of benefits in attending the support groups. Primarily for people with mental illness, finding a 
safe place is difficult. Hence, support groups are seen as places where they could go out and meet with people experiencing the same issues. My own practice experience and lessons from the literature suggests that support groups offer some great things to people's lives which may include:

-Feeling less lonely, isolated or judged

-Finding a purpose in life

-Being interested in and having a desire to do something

-Gaining a sense of empowerment and control

-Improving one's coping skills and sense of adjustment

- Talking openly and honestly about your feelings

-Reducing distress, depression or anxiety

-Developing a clearer understanding of what to expect with the situation

-Getting practical advice

-Someone to listen to your stories that are untold

-A place to meet and make new relationships

By engaging in the group, members gain skills in increasing their social equality and the control they may exert over their own lives whilst gaining security and a sense of community as a result of a raised group consciousness (McDermott, 2002).The group program is suited to individuals affected by mental health issues that seek peer support in a compassionate and holistic educational setting in addition to medical or psychological interventions with which they may be involved (Aneshensel \& Stone, 1982; Queensland Health, 2010).The support group is aimed at empowering individuals to achieve a sense of control of their lives through sharing with others that have experienced similar changes (Aneshensel \& Stone, 1982; Brewis, 2007). Although each individual experiences changes in mental capacity due to depression in their own unique way (Goldsworthy, 2005), they have unique capacities upon which they can draw as they adjust to their new situation and the feelings that can accompany those changes (Rosenblatt, 1998). Through participation in the activities of the group-work activities the group will explore together the feelings around each individual's changes, and together facilitate each other's recognition of their power to choose (Healy \& Walsh, 1997). Toseland and Rivas (2009) suggest that group work is useful for harnessing the capacities and resources of individuals for achieving individual, group and community goals through intentional intervention and group process strategies.

Due to the significant impact of mental illness, treatment is usually long term, multimodal and multidimensional (Gerrity\& Peterson, 2004).Group work is an adjunct to counselling, enabling survivors to share their feelings and experiences with people who have similar experiences and can listen and understand. (Lew, 2010).Group work can facilitate the powerful telling of the story; a "... group provides a safe haven...connected without exposing yourself to the rest of the world" (Lew, 2004, p, 233).Thus it demonstrates the need of such groups in places and contexts where services are rare.

\section{Process of Building this Relationship}

The question arises here as to how did this group got established? What was the process involved? What impact did it have on its members etc? It is acknowledged that the process of building relationships with the members of the group was very crucial in developing this support group. This took a lot of time and energy (both from consumers and facilitators side to make it a reality) as it involved gaining a sense of trust. But it all started with a simple thing. Calling the participant by name and respecting him/her as an individual. It was the person who was important rather than seeing the person as a problem. This paradigm shift from pathology to recognizing the strength of each individual changed the environment of the group. This strengths based approach (Francis, 2012; Pulla 2012) became a culture within the group which was later incorporated in the group norms of the team. There is no short cut to building relationships, but being honest, transparent, and committed to the cause is very important in this process. In this context, one of the group members noted that -

"We come to this group ...Because we feel it is our own and we can decide to do what we want to do. There is no pressure or compulsion to do things. I feel quite safe here and I am listened to. No one makes fun of me and I am respected. I look forward to coming to this group" (Participant)

This can be built also by engaging the participants in a meaningful way. Choosing activities that promote self-respect, resilience, and hope can be a good tool that any facilitator can use to build this alliance with the group members. This has the greatest healing potential. As Bland etal. suggest the helping relationship- between workers and consumers and between workers and families is seen as fundamental to the healing process (2009). Thus it is the role of both the facilitator and members to strive towards achieving this in the process. A facilitator may have to lead the way and the members will follow as this will eventually become the unwritten norm of the group; to experience healing and to allow others to experience it as well. Hence establishing such meaningful and purposeful relationships was a priority for the group. The group created that space and enabled it to happen, the group was open to listening, sharing stories, and showed interest in the lives of others. This positive environment allowed them to laugh, smile, and cry and overall helped them to be what they are. This has had a great impact on each of the members' lives. As one of the members narrated-

"It has been a long time since I had a good laugh... it is just because we know each other and can go out together .... I know for sure, I will not be judged" (Participant)

\section{And why was this needed?}


Fiona McDermott in Inside Group Work suggests that social isolation and exclusion have been proven to have negative effects on a person's health and mental health (2002). Contemporary studies into social engagement and depressive symptoms in late life support claims that social isolation and loneliness increase symptoms, but the amelioration of these stressful conditions through programs like support groups, can improve health as well as quality of life amongst ageing populations (Glass et al. 2006; Clare Wenger et al. 1996). Research suggests that employing a group rather than an individual approach in working with older adults is desirable as the setting enhances both communication and expression (O'Leary \& Barry, 1998). McDermott discusses the idea that in forming groups, workers are facilitating the creation of a resource system that can increase members' access to many resources; including knowledge, power, experience and networks (2002). Barr and Russell include these resources within their discussion of social capital surrounding ageing individuals and their social environment; suggesting that social networks play an important role in later life, particularly in supporting older people to remain independent in their community, despite the onset of chronic disease and disability (Barr \& Russell, 2006, p.211).

The research cited above supports the assertion that increased connectivity for elderly people through a skills-based socialisation group as discussed, contributes significantly to increasing access to critical social capital; leading to improved health and wellbeing (Barr \& Rusell, 2006; Glass et al., 2006; O’Learly \& Barry, 1998; Wenger et al., 1996). So, the applications of group work in various contexts are justified and there is a real need when people are socially isolated or affected by a mental health condition.

\section{Theoretical Approaches}

This broad construct came about as a result of the emergence of the population health approach. The aim of the population approach to mental health is to promote health and wellbeing and intervene early in the pathways to mental illness through strategies involving individuals, communities and whole population groups by raising awareness though education and by providing a comprehensive range of high-quality, integrated health promoting and biomedical services, while striving to achieve equity of health status, health resource allocation, access and utilisation across the population (Commonwealth Department of Health \&Aged Care, 2000, p. 20).The sphere of social work in mental health is that of the social context and social consequences of mental illness (AASW, 2004). From this perspective, in order to provide appropriate assistance to people with mental health issues it is vital that social workers understand that psychosocial and economic conditions and consequences are inextricably linked to the mental health continuum (Bland, Renouf, \& Tullgren2009).

In contrast the medical profession continues to be dominated by how mental health issues are understood and treated (Bland et al.,2009) and the medical industry is dominated by the economic and ideological perspectives of pharmaceutical organisations supporting the notion that issues in living can be explained from a biomedical perspective, whileconceptualizing interventions based on research directed at discovering the underlying genetic, chromosomal, or biochemical causes for people's difficulties (Eriksen \& Kress, 2005).

Congruent to the above processes is the value and belief that service users are the experts of their own experiences and any action taken on their behalf should be framed in their experiences and understanding (Bland et al.,2009). These concepts are in line with the social justice domain as set out in the competency of standards for mental health social workers (AASW, 2004, pp.22-23) and the AASW code of ethics (2010).

Structurally, the mental health system is still dominated by the illness driven model (Stacey \& Herron, 2002) The reality is that for our service to maximize positive consumer outcomes a comprehensive knowledge of, and networks with, local community associations, businesses and human service providers are vital (Bland et al.,2009).Utilizing a community development framework (Ife, 1995) to promote social inclusion and raise awareness of the issues confronting people with mental illness, is another key strategy for building creative partnerships and accessing community assets such as community champions and local resources. Support groups can make use of such community resources which will help its members to become active players in the community. In addition, establishing strong and effective professional relationships with mental health practitioners and service providers will assist in reducing barriers to services for the client group and identify opportunities to establish links with local communities.

Following are two case studies that illustrate the group processes and the importance of being part of a group.

\section{Case Study 1}

Mr Sam has been diagnosed with a major mental illness and has many times attempted to self-harm and suicide. After the last discharge from the hospital he relocated himself to a rural town where he was living with his friends. Upon hearing about the support group, he came to the group quite reluctantly and managed to remain there for some time without much social or group interaction. This continued for some time. He would very often sit and watch things or make a cup of coffee and read. Gradually he became interested in giving a hand in preparing lunch. We could see a gradual change in him; he started to talk to people, exchange greetings and offered to help with transport in getting people to the group. This was seen as a huge change in his lifestyle. However, in the middle of all these changes, he again tried to kill himself and was admitted to the local hospital. The group members, when they came to know about it, felt very sad and 
were upset over the incident. But, suddenly one of the participants said "come let us go to the garden and pick up a few flowers and go to visit him in the hospital". As a facilitator of the group, I was really moved by this gesture of compassion and love for the member of the group. Indeed the group members visited him at the hospital, which was a turning point in the life of Mr Sam. He said later "I was so happy to see the group members beside my bed at the hospital and I knew I was being cared for, this was a great feeling when I was on the hospital bed. Great to know that there are people behind me". From the eyes of many, it may have only been a visit to local hospital but how this simple gesture has played a vital role in the life of a group member is quite unique. He was later discharged and was known to be an active member since then.

\section{Case Study 2}

Mrs Dona has been a regular visitor to the support group for some time now. Usually she will not miss any of the opportunities that are made available to the participants. The other members looked at her for support and comfort. She would often engage in conversation with members and particularly with new comers in the group. During the course of time in the group, Dona had to face many personal challenges and tragedies including the death of her dear ones, and she also had to manage and live with her mental illness. She embraced them all with great pain and sorrow .But she would often share her stories with others in the group and the group showed a sense of empathy and provided her with a patient hearing, not being judgmental. It was indeed a safe place for all to be together and support each other. In times of crisis, like Dona, many others used this opportunity to discover themselves and experience a sense of relief, because of the powerful relationships and trust that existed in the group.

(Note: The names of the group members are changed here to protect their privacy. Only a simple anecdote has been mentioned here to illustrate the story. )

Having a major mental illness has always been a stumbling block in Dona's life as she would say - "it has taken my whole life". But what makes me live now is the group that I belong to. "I now get up because I know I can go to my group today". "This is the life line of my life. This group has not only given me a sense of belonging, purpose in life but an inspiration to support others in their difficult times. I am happy that I am a member of this wonderful group where I get to meet and interact with people like me, who understand me and provide me with support without questions".

\section{The Practitioner's Reflections}

As a practitioner I have always held a belief that change is possible and every individual comes with great resources and potentialities. What is important is with which eyes we see our clients. As Steven Onkan in his key note address at a conference on "Exploring relationship in mental health "in Perth, Australia stated "When you change the way you look at things, the things you look at change" (Onkan, 2012).This is quite remarkable for a practitioner who has been trained to look at the deficits and is now challenged to look beyond the illness model and appreciate the strengths of the clients. Having embraced this ideological shift myself, I was deeply inclined to encourage the participants to appreciate the efforts clients made on their way to recovery. (Francis, 2012). The strengths based philosophy, combined with personal passion to support the clients was also seen positively by the participants themselves. It was not the practitioner who was important but the members as they developed plans, programs and of course decided on the path they wanted to travel.My assistance was limited, so long as they got their plans sorted out. It was a participatory planning process, a sense of mutual respect and reciprocity that helped them plan well. The other striking point to mention here is the overarching community development principles that the practitioner has been using to elicit a community response about mental health issues in a rural community. On reflection I find that the community itself had adopted the support group and supported the group in many ways. The community provided a place to meet (when it was needed), offered donations and materials for the group, provided referral services and supported and linked them with community events and programs. The support group members were invited to cater to the local events which are a true demonstration of the inclusive relationship that was developed gradually in the region. As a practitioner, I took pride in talking about the group to my other clients, groups, management, and to the public .This not only gave the group a sense of power but assisted them in assuming greater responsibility towards the work. As McDermott points out "Group is a power house " $(2002$, p.37) it has the power to make necessary changes or bring about change in the area. This group that I am referring to here not only was a power base but was also a container of individuals and promoted social change in the area .An example of creating sustainable change in the community, in the area, or in mental health issues at a time when it was seen as a taboo to be explicitly discussing it. The social stigma attached to mental health was by and large addressed by the people themselves who had been diagnosed, with the support of the local community leaders, safety net groups, NGO's, and Community mental health teams.

It is also important to reflect on the relationship that existed between the social worker and the clients and among the clients themselves. It was not a relationship that was dictated by power, status or titles but rather it was based on a belief in humanity, based on trust, companionship and compassion. But I must admit that there were some occasions I had to use my clinical judgments to intervene in 
situations that demanded my power or title of the profession. The members themselves followed a group norm which was based on dignity, respect and mutual support. The members believed in the following words. As a group we needed "Something to do, something to love and something to look forward to". These powerful words provided a great momentum to the group's thinking and planning. As a practitioner, I truly believed and witnessed the power of groups in the lives of people especially from the beginning stages; the way connections are made, how the relationship is built, how an environment of trust is nurtured and how the members explore and experience the healing power of relationships. I have seen it over and over and I wondered often as to what is the magic behind this - the lessons from the field have taught me that it is nothing but the 'healing power' of relationships that exists in the groups. I also thought that group facilitators should support the sharing of feedback and experiences, encourage the group members to see each other as a respected source of mutual learning and aid, rather than having the facilitators play the role of an expert. Respecting the intelligence and resources a group of people bring strengthen the nature of the group process. Social work writing indicates that social work groups focusing on process and dynamics as "natural vehicles for empowerment" (Breton, 1994).

\section{Below are Some of the Lessons from the Field which I Have Alluded to in this Paper}

\section{Lessons from the Experience}

Working with consumers at the support group has been challenging, thought provoking, interesting and a worthwhile and satisfying human experience. It taught me as a worker to understand the real life situations of the consumers and made me aware of the numerous challenges that they have to face every day. I say this because they have allowed me to be a companion in their journey and have shared some of their personal stories. I am humbled to learn many things from my group members; they taught me some of the most important lessons in recovery and I learned that no matter what I do ... I need to be a great listener to members and be honest with the members. I was indeed touched by the incredible positive attitude consumers maintained even in the midst of some great challenges they faced and indeed this was an eye opener for me. Respecting the members at all times is crucial in any kind of work with groups. Respect is very important as people who make up their mind to attend such programs may have had bad experiences. Welcome them with open hearts, listen to them carefully, and work with them non- judgmentally. Hence plan the program with great care and involve the members in the process and let them become the drivers of the program. At the same time as being a professional, it is important to have an ideological framework for practice. This research informed practice will guide the practitioners to measure the impact of the program and enhance the quality of services.

I must also admit that, during this process of establishing and facilitating the groups we also faced some challenges. They appeared at different times, and different points of the progress of the group. Some of the challenges were related to obtaining resources for the group, leadership issues, organisational concerns, safety concerns, ideological issues, issues of confidentiality and gender issues. As a group, we talked about these issues more openly and such questions and issues provided opportunities for the group members to enter into valuable discussions of purpose of the group (Kurland \& Salmon, 1998, p. 9).This process of naming the issues and open discussion helped establish trust, friendship and relationship among the participants.

\section{The Philosophy}

One of the lessons from the experience has been to acknowledge the steps people with mental illness take to be part of the groups and society at large. Their contribution towards recovery and progress is very often underestimated. This realisation has helped us all to appreciate the smallest efforts our group members take to achieve their personal goal,no matter how small the goal or plan this be in the eyes of others. So learning to appreciate this growth and recovery has been embedded in the whole group work process. This has been seen by both consumers and the mental health workforce as a step towards creating a meaningful space for all the consumers. The group provided a safe environment for all the members. This indeed generated a lot of positive energy and enthusiasm among members.

\section{The Practice and the Ownership}

The practice was guided by social work practice standards. Social work is committed to three core values and they are "Respect for persons, Social Justice and Professional integrity" (AASW, 2013, p.7).All were treated with great respect and compassion. The environment was such that they felt comfortable and each member of the group tried to create that same environment for all. This was facilitated by the author initially, but gradually the members themselves took charge for organising activities and programs. This was again an example of growth and development for the group. Because the group took it up as their own work which was really an achievement by the group. Gradually the project had become their own as they took control of the day to day functioning of the group with minimal support from the supporting agencies.

\section{The Community Support}

The community support that we received to establish and sustain this group was magnificent. This inclusive community development approach that led to the successful 
outcome of this support group is to be acknowledged as we draw lessons from this experience. The community expressed its support and appreciation by sponsoring, allowing us to use facilities, and of course by their presence at the support group activities. The community approach had a great impact on the service delivery of the support group. In a nut shell, we can say that the support of the local community helped the support group to sustain over the last 7 years.

\section{Member's Willingness to Contribute and to Belong}

This is yet another lesson learnt from the experience. Members were aware that the community and the supporting agencies have been greatly responsible for the effective running of the support group along with the support of the local mental health team. Hence, the members expressed their willingness to contribute back to the community by volunteering ,being a local support at the clubs, schools and other community functions. At one point, the support group was invited to cater for a local event in the community which was a true example of community reciprocity and genuineness. This not only raised a greater appreciation for the community by the support group but it enhanced the morale of each participant. Yes, I now know... I belong to a community. The lesson is that - communities do play a vital role in the recovery of people with mental illness.

The strengths of the group

Each member comes to the group with his/her own personal values, issues, hopes and plans and the group provides an opportunity for each of them to experience and explore their own growth through mutual aid. This perspective sees "... the group itself as a powerful force acting to affect individual behavior" (McDermott, 2002, p. 43). Secondly, the group as a container of individuals, which is a contrast to the above viewpoint, sees it as "...individual differences and similarities are recognized as powerfully affecting the group" (McDermott, 2002, p. 43). In my observation, this group was not seen by the general community as ' a group of people with mental illness' but rather people who are keen to support one another on their way to recovery and yet wanting and willing to contribute back to community life. The strength of the group was that they were able to sit together and plan their program, decide on leadership and other roles, and were able to manage their day today activities, represent the group at various forums, advocate on behalf of the group to raise awareness about mental health, and seek further funding to support their initiatives. The group actually moved to the stage which McDermott calls "Group as a power base" (2002, p.66). They came together and worked together to achieve their goal. Group members relied on each other's strength to build on further and hence created a collective sense of belonging and hope in the group. In this context, Lindsay and Orton explain that

The role of the facilitator is of crucial importance and the self-efficacy is unlikely to develop if the facilitator does not also firmly believe that positive change is possible and likely. The facilitator also has an important role to play in building self-efficacy in the group, for example emphasizing members' strengths and capacity to change ... (2011, p. 11)

It is important for the facilitator to have a firm belief in the strengths of people. By recognising the strengths of each member and the group, the facilitator is able to establish group cohesion and culture. Groupcohesiveness is the force bringing group members closer together (Toseland \& Rivas, 2012, p.70) Francis,(2012) states that

At the heart of the strengths-based approach are social justice principles of 'power with', respect and the 'ownership' by the client of their own process of change. The strength perspective is based on the belief that every person, family and community has capabilities that can be drawn on to overcome problems, and that trauma, illness and struggle present opportunities for challenge and growth. It is also based on the principle that in every environment, people, groups and institutions have something to offer. Here, the focus is on the person's strengths, not pathology, symptoms, weaknesses, problems or deficits. (p.26)

This ideological framework has not only benefited the group formation, structure and actual facilitation of the program but has also helped each of the participants to believe in themselves and work with each other to progress on their individual journey towards recovery. In this situation, the ultimate strengths manifested by the participants is that they made a decision to come and that is a great move on their part to get out from their comfort zone to be in the company of others who have encountered similar issues in their life. This initiative of the participant is then supported, nurtured and supported in an environment of hope and positivity.

\section{Conclusion}

Support groups have had a tremendous impact on the lives of people described in this paper. Some are big and some are small. But most of the members have experienced a sense of hope and purpose in their life and feel connected to group members. It is argued that these changes, however small or big, that group members have experienced is achieved and built on the foundation of relationships and strengths and it is conceptualised here as healing. Healing here reflects not the physical recovery from the illness, but a sense of hope and courage that people feel that they are not alone in their journey, experience a sense of control over their life, and feel confident to move on their journey towards recovery (Francis, 2012).This miracle of transformation can occur in any support groups. Hence, the author using vignettes has shown the power of the group and how it can influence members by highlighting the experiences of participants. A 
shift in focus from deficit to strengths takes into consideration that people do have strengths, skills, and abilities. This has been the key element of discussion throughout this paper. It also emphasised that relationship building is crucial in this situation. It needs an environment of support, co-operation, and partnership that can foster hope, as hope is the foundation of recovery (Gehart, 2011).However, more needs to be done in social work practice especially in embracing the philosophical shift in practice and in developing appropriate practice frameworks which are evidence based. That can only happen if practitioners engage in critical reflection, engage with clients in meaningful ways in establishing collaborative research and to scientifically measure the impact such groups make in the lives of people with mental illness. This is both a challenge and opportunity for the social work profession.

\section{Notes}

1. Names of individuals and organizations have been changed because of confidentiality concerns.

2. Support groups are also known as mutual aid groups. These terms have been used interchangeably in this article

3. The focus of this paper is to show case the group process and how it had an impact on the lives of people with a mental illness.

\section{REFERENCES}

ABC News. (2010, December 8.) Qld spends too little on mental health: Advocates. Retrieved March 152011 from http://www.abc.net.au/news/stories/2010/12/08/3087932.htm

Aneshensel, C. S., \& Stone, J. D. (1982). Stress and depression: A test of the buffering model of social support. Arch Gen Psychiatry, 39(12), 1392-1396.

Australia Association of Social Worker (AASW). (2013). Practice standards, Canberra City,ACT,ISBN:978-0-9808661-9-3

Australia Association of Social Worker (AASW). (2010).AASW Code of Ethics,ACT: AASW.

Australia Association of Social Worker (AASW). (2004).The development of competency standards for mental health social work. ACT: AASW.

Barnes, S. (2001). Working with, and for, our seniors: Is local government leisure provision keeping up with the ageing population? Journal of Leisure Properties, 2 (2), 166-179.

Barr, F. M., \& Russell, C. A. (2006). Social capital: A potential tool for analysis of the relationship between ageing individuals and their social environment. Ageing International, 31 (3), 203-216.

Birnbaum, M., \& Cicchetti, A. (2008). The power of purposeful sessional endings in each group encounter. Social Work with Groups, 23(3), 15.
Bland, R., Renouf, N., \& Tullgren, A. (2009).Social work practice in mental health: An introduction.Crow's Nest, NSW:Allen \& Unwin.

Breton, M. (1994). On the meaning of empowerment and empowerment-oriented social work practice.Social Work with Groups, 17, 23-38.

Brewis, R. K. (2007). A voice and a choice self directed support by people with mental health problems: A Discussion Paper (pp. 62). United Kingdom: In Control.

Bundey, C., Cullen, J., Denshire, L., Grant, J., Norfor, J., \& Nove, T. (2008). A manual about group leadership and a resource for group leaders. Nth Parramatta: Western Sydney Area Health Promotion Centre.

Burks, V. K., Lund, D. A., \& Hill, R. D. (1991). Factors associated with attendance at caregiver support group meetings. Activities, Adaptation and Aging, 15(3), 93-108.

Campbell, J.,\&Davidson, G. (2012).Post qualifying mental health social work practice.London: SagePublications.

Clare Wenger, G., Davies, R., Shahtahmasebi, S., \& Scott, A. (1996). Social isolation and loneliness in old age: Review and model refinement. Ageing and Society, 16, 333-358.Coppock, V.,\&Dunn, B. (2010). Understanding social work practice in mental health. London: Sage Publications.

Engleberg, I., \& Wynn, D. (2007). Working in groups: Communication principles and strategies (4th ed.). United States of America: Houghton Mifflin Company.

Eriksen, K.,\& Kress, V.E. (2005). The price of diagnosis in beyond the DSM story: Ethical quandaries, challenges and best practices. London: Sage.

Francis, A. (2012). 'Journey towards recovery in mental health' (pp. 19-33). In V. Pulla, L. Chenoweth, A. Francis, \& S.Bakaj (Eds .), Papers in strengths based practice. New Delhi: Allied Publishers.

Gehart, D. (2011). The mental health recovery movement and family therapy Part II: A collaborative approach for supporting mental health recovery. Journal of Marital and Family Therapy, 38.doi:10.1111/j.1752-0606.2011.00229.x

Gerrity, D.,\& Peterson, T. (2004). Groups for survivors of childhood sexual abuse (pp. 97-117).In J. DeLucis Waack et al.(Eds.), Handbook of group counselling and psychotherapy. Thousand Oaks, CA: Sage Publications.

Glass, T. A., Mendes de Leon, C. F., Bassuk, S. S., \&Berkman, F. F. (2006). Social engagement and depressive symptoms in late life: Longitudinal findings. Journal of Aging and Health, 18 (4), 604-628.

Goldsworthy, K. K. (2005). Grief and loss theory in social work practice: All changes involve loss, just as all losses require change. Australian Social Work, 58(2), 167-178. doi: 10.1111/j.1447-0748.2005.00201.x

Healy, K., \& Walsh, K. (1997). Making participatory processes visible: Practice issues in the development of a peer support network. Australian Social Work, 50(3), 45 - 52.

Hughes, M. (1995). Bereavement and support: Healing in a group environment. Washington: Taylor \& Francis Inc.

Human Rights and Equal Opportunity Commission. (1993). Human rights and mental illness: Report of the national inquiry into the 
human rights of people with mental illness. Canberra: HREOC.

Humphrey, G. M., \& Zimpfer, D. G. (2008). Counselling for grief and bereavement. London: Sage.

Hyde, B. (2013). Mutual aid group work: Social work leading the way to recovery-focused mental health practice. Social Work with Groups, 36(1), 43-58. doi: 10.1080/01609513.2012.699872

Ife, J. (1995).Creating community alternatives - Vision, analysis and practice.South Melbourne: Addison Wesley Longman Australia Pty.

Kurland, R., \& Salmon, R. (2006). 'Purpose: A misunderstood and misused keystone of group work practice. Social Work with Groups, $29(2), 105-120$.

Lefley, H. P. (2009). A psychoeducational support group for serious mental illness.The Journal for Specialists in Group Work, Vol. 34(4).

Lew, M. (2004). Victims no longer: The classic guide for men recovering from sexual child abuse (2nd ed.). New York: Harper.

Lindsay, T., \& Orton, S. (2011). Groupwork practice in social work (2nd ed.). Exeter: Learning Matter Ltd.

McDermott, F. (2002). Inside group work - A guide to reflective practice. Crow's Nest: Allan \& Unwin.

McWilliams, S., Egan, P., Jackson D., Renwick, L., Foley, S., Behan, C., Fitzgerald, E., Fetherston, A., Turner, N., Kinsella, A., \& O'Callaghan, E. (2010). Caregiver psychoeducation for first-episode psychosis.European Psychiatry, 25, 33-38. doi: 10.1016/j.eurpsy.2009.08.006

Mohr, W.K.(2003). Surfacing the life phases of a mental health support group. Qualitative Health Research, 14,(1), 61-77. doi: $10.1177 / 1049732303259663$

Mohr, W.K.(2003). The substance of a support group. doi: $10.1177 / 0193945903253982$

Murphey, C. M., Shillingford, A. (2012). Supporting unemployed, middle-aged men: A psychoeducational group approach. Journal of
Employment Counseling 49(2), 85-96.

Onken, S. (2012). Key note presentation at 2012 ASPAC conference Exploring relationships in mental health, Perth, Australia, June 11-13, retrieved from https://www.rfwa.org.au/

O’Leary, E., \& Barry, N. (1998). Reminiscence therapy with older adults. Journal of Social Work Practice, 12 (2), 159-165.

Pulla, V. (2012). 'What are Strengths based Practice all about? In Pulla, V., Chenoweth, L., Francis, A., Bakaj, S. (eds) . Papers in Strengths Based Practice, New Delhi: Allied,Publishers ISBN 978-81-8424-810-4

Queensland Health. (2010). Queensland health policy site. Retrieved July 20, 2011.

Rosenblatt, P. C. (1998). Living beyond your losses: The healing journey through grief.Journal of Palliative Care 14, 71-72.

Schneider, C. M., \& Corey, G. (2006). Groups: Process and practice (7th ed.). Belmont, CA: Thomson/Brooks/Cole.

Sharfstein, S. S. (2005). The healing power of relationships. Psychiatry: Interpersonal and Biological Processes, 68(3), 212-213

Svavarsdottir, S. J., Olafsdottir, K. V., Sturludottir, E., \& Juliusdottir, S. (2012). Psychiatric group work in social skill training. Social Work with Groups, 35, 103-123. doi: 10.1080/01609513.2011.602221

Toseland, R. W., \& Rivas, R. F. (2009).An introduction to group work practice. Albany: Pearson/Allyn and Bacon.

Toseland, R. W., \& Rivas, R. F.(2012).An Introduction to Group Work(7thed.) Needham Heights, MA: Pearson Education Company.

Wodarski, J. S.,\& Feit, M. D. (2012). Social group work practice: An evidence-based approach. Journal of Evidence-Based Social Work, 9, 414-420. doi: 10.1080/15433714.2012.695719

Yalom, I., \& Leszcz, M. (2005). The theory and practice of group psychotherapy (5th ed.). New York: Basic Books. 